Document downloaded from:

http://hdl.handle.net/10251/101068

This paper must be cited as:

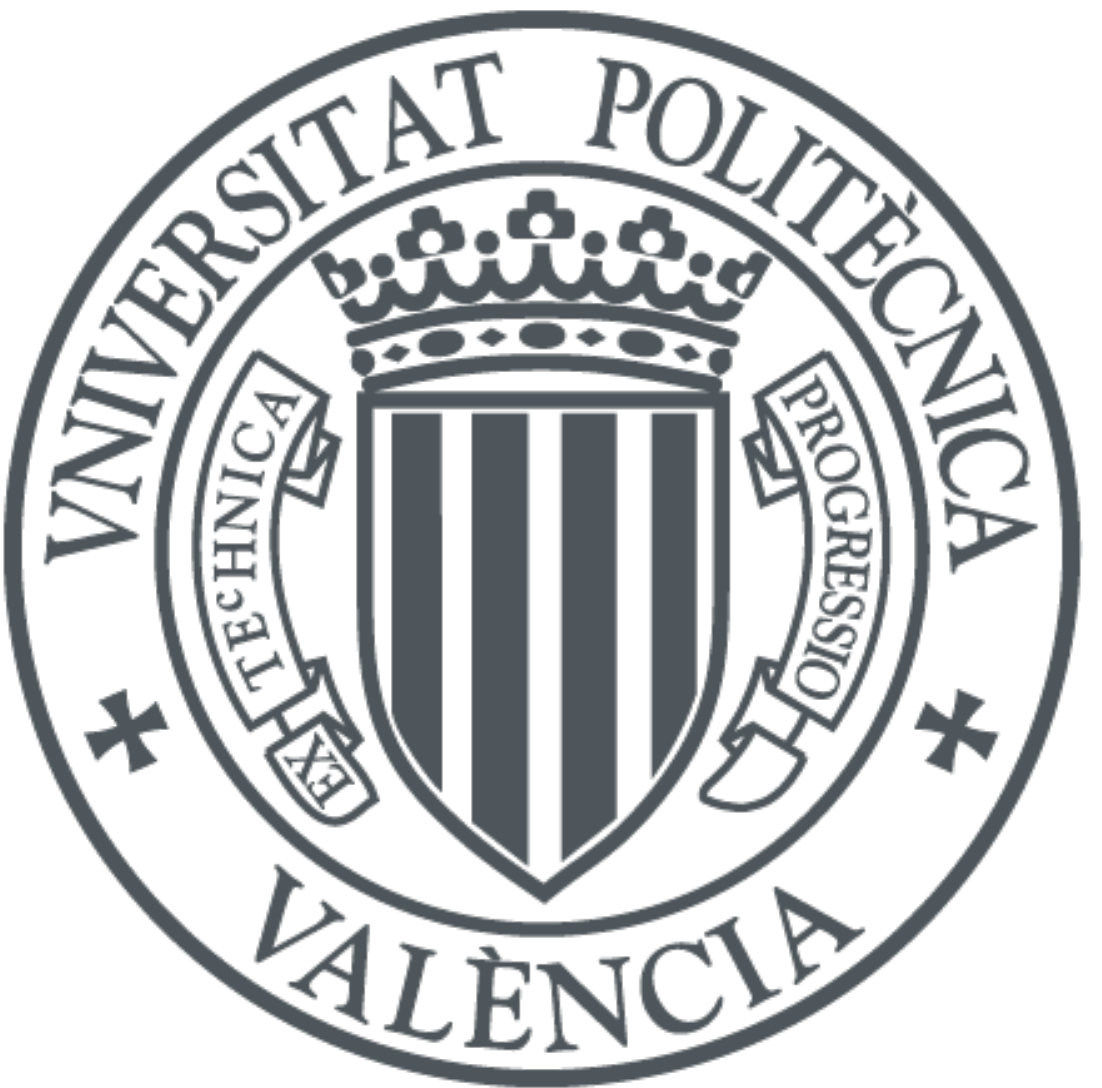

The final publication is available at

http://doi.org/10.1016/j.apcata.2017.08.018

Copyright Elsevier

Additional Information 


\title{
Isotopic H/D Exchange on Graphenes. A Combined Experimental and Theoretical Study
}

\author{
German Sastre ${ }^{1}$, Amparo Forneli ${ }^{1}$, Valer Almasan ${ }^{2}$, Vasile I. Parvulescu ${ }^{3}$ and Hermenegildo \\ $\operatorname{Garcia}^{*}, 1$ \\ ${ }^{1}$ Instituto de Tecnología Química CSIC-UPV, Universitat Politécnica de Valencia, Av. De los \\ Naranjos, 46022 Valencia, Spain
}

2 INCDTIM Cluj-Napoca, Str. Donat nr. 67-103, PO 5 Box 700, 400293 Cluj-Napoca, Romania

${ }^{3}$ Department of Organic Chemistry, Biochemistry and Catalysis, University of Bucharest, B-dul Republicii 4-12, Bucharest 030016, Romania

\begin{abstract}
Adsorption of $\mathrm{H}_{2} / \mathrm{D}_{2}$ on graphene $(\mathrm{G})$, graphene oxide $(\mathrm{GO})$, single walled carbon nanotube (SWCNT), N-doped graphene [(N)G], and a sample of active carbon (C) has led to the detection of HD, indicating dissociative chemisorption of hydrogen on the surface of the material. The amount of HD detected follows the order $\mathrm{G}>\mathrm{SWCNT}>\mathrm{GO} \sim(\mathrm{N}) \mathrm{G} \sim \mathrm{C}, \mathrm{G}$ giving about five-fold higher $\mathrm{H}_{2} / \mathrm{D}_{2}$ adsorption and HD exchange level than SWCNT and about ten-fold larger values than that of the other samples. Quantum-chemistry calculations modeling a carbon atom vacancy on a $\mathrm{G}$ cluster estimates an activation barrier for $\mathrm{H}_{2}$ dissociation of ca. $84 \mathrm{~kJ} / \mathrm{mol}$ for a mechanism involving under coordinated carbon atoms at the defect site.
\end{abstract}


KEYWORDS. Heterogeneous catalysis, Metal-free catalysis, Graphenes as catalysts, Graphene as hydrogenation catalyst, Hydrogen-deuterium isotopic exchange, Carbon vacancies as active sites. 


\section{Introduction.}

For the sake of sustainability, there is much current interest in developing graphene and related materials as metal-free catalysts. ${ }^{1-4}$ The use of graphenes as carbocatalysts could be an alternative to catalysts containing noble or critical metals. While ideal graphene is devoid of active centers, the presence of carbon vacancies, oxygenated functional groups or heteroatoms as well as the periphery of graphene sheets can act as catalytic sites for certain reactions. ${ }^{3}$ One of the targets in the area of carbocatalysis by graphene is to show that, by engineering of the material and generation of defects, active sites of the required nature can be produced in high density in graphenes to increase their activity achieving catalytic performances in the range of those typically promoted by transition metals.

Although there are a few scattered examples of organocatalysts, ${ }^{5-7}$ hydrogenations of multiple bonds is commonly performed using transition metals, frequently noble and precious metals, as catalysts. ${ }^{8}{ }^{9}$ Recently, it has been reported that defective graphene can act as carbocatalysts for hydrogenation of alkenes, acetylene and nitro groups. ${ }^{10}$ In these hydrogenations, the key elementary reaction is activation of the strong, apolar $\mathrm{H}-\mathrm{H}$ bond. Previous thermogravimetric data reported in the literature have found that the $\mathrm{H}_{2}$ uptake of thermally exfoliated graphene (with a specific surface area of $500 \mathrm{~m}^{2} \times \mathrm{g}^{-1}$ ) is about $0.5 \mathrm{wt} \%$ at 77 $\mathrm{K}$ and 1 bar. ${ }^{11}$ This low $\mathrm{H}_{2}$ uptake indicates that the interaction between graphene and $\mathrm{H}_{2}$ should be very weak and it has been determined that the isosteric heat of $\mathrm{H}_{2}$ adsorption on graphenes is about $5 \mathrm{~kJ} \times \mathrm{mol}^{-1} \cdot 12$

Considering the interest of $\mathrm{H}_{2}$ storage, modified graphenes have also been prepared with the aim of increasing the $\mathrm{H}_{2}$ adsorption capacity of these materials. ${ }^{13-15}$ However, although 
formation of graphane by hydrogenation of graphene has attracted considerable attention, ${ }^{16,17}$ the absence of studies proving the possibility to promote H/D isotopic exchange by graphenes is remarkable.

Considering the importance of hydrogenation, both from the fundamental and industrial point of view, it is of interest to gain understanding on how graphenes can catalyze hydrogenations, particularly, how molecular hydrogen can become activated by defects on graphenes and what can be the active sites for this process. This study presents the results of an experimental study of the occurrence of $\mathrm{H} / \mathrm{D}$ scrambling and $\mathrm{H}_{2}$ activation on various graphenetype materials, combined with theoretical calculations of how this scrambling can occur by the interaction of $\mathrm{H}_{2}$ with carbon atom vacancies.

\section{Catalysts.}

The list of materials submitted to evaluation with regard to their activity in H/D isotopic exchange, including their origin and main physicochemical characterization are provided in Table 1. The series includes a defective graphene (G) derived from pyrolysis of alginate at 1000 ${ }^{\circ} \mathrm{C}$ that was found in our previous study among the most active C-C multiple bond hydrogenation catalysts. ${ }^{10} \mathrm{G}$ contains a residual percentage of $\mathrm{O}$ that was determined by chemical analysis as well as carbon vacancies generated by $\mathrm{CO}_{2}$ evolution during the pyrolytic formation of $\mathrm{G}$. Raman spectroscopy shows the presence of the 2D, G and D bands characteristic of this type of defective graphene with an $I_{G} / I_{D}$ intensity ratio of 1.13 , that gives a quantitative estimation of the presence of defects.

Another related sample [(N)G in Table 1] was obtained by pyrolysis of chitosan at $1000{ }^{\circ} \mathrm{C}$ and besides residual $\mathrm{O},(\mathrm{N}) \mathrm{G}$ also contains $\mathrm{N}$ in its composition. For the sake of comparison the 
study includes also a graphene oxide (GO) obtained from graphite by Hummers oxidation to graphite oxide and subsequent exfoliation. In the related precedent, it was found that GO was unable to promote C-C hydrogenation. ${ }^{10}$

The series of carbocatalysts also includes a sample of single walled carbon nanotube (SWCNT). In principle SWCNT could behave similarly to graphene in those cases in which the curvature of the wall does not play a role. There are in the literature abundant examples showing a similar behavior of SWCNT and graphenes as carbocatalysts. ${ }^{3,}{ }^{4}$ However, since the preparation procedure and precursors of SWCNT are totally different to those of graphenes, other factors such as metal impurities present in SWCNT due to the incomplete removal of the large catalyst amount, the wall curvature and aspect ratio or the lower O content of SWCNT compared to $\mathrm{G}$ have to be considered as potential sources of a contrasting behavior between $\mathrm{G}$ and SWCNTs.

Other material that was included in the study is a commercial active carbon (C), whose structure and composition are ill-defined and different from that of 2D graphenes or 1D cylindrical SWCNT. Overall, the set of samples was selected to include not only an active hydrogenation catalyst of C-C multiple bonds as G, but also to determine the influence of $\mathrm{N}$ doping and the presence of $\mathrm{O}$, as well as to allow comparison with SWCNT and active carbon for the H/D isotopic scrambling. $G$ and (N)G have been characterized in the literature ${ }^{18,19}$ as it happens also for GO, ${ }^{20,21}$ while SWCNT and C are commercial samples. The main analytical and textural data of the materials tested are provided in Table 1. 
Table 1. List of carbon containing materials used in the present study, their preparation procedure and main analytical and textural properties.

\begin{tabular}{|c|l|l|l|}
\hline Material & Preparation & $\begin{array}{c}\text { Composition, } \\
\text { wt. } \%\end{array}$ & $\begin{array}{c}\text { Surface area, } \\
\mathrm{m}^{2} \mathrm{~g}^{-1}\end{array}$ \\
\hline $\mathrm{G}$ & Pyrolysis of alginate at $100{ }^{\circ} \mathrm{C}$ & $\mathrm{O}: 15$ & 250 \\
\hline $\mathrm{GO}$ & $\begin{array}{l}\text { Hummers oxidation of graphite } \\
\text { and exfoliation }\end{array}$ & $\mathrm{O}: 46$ & 246 \\
\hline$(\mathrm{N}) \mathrm{G}$ & Pyrolysis of chitosan at $1000^{\circ} \mathrm{C}$ & $\mathrm{N}: 5 ; \mathrm{O}: 13$ & 257 \\
\hline SWCNT & & O: 3 & 1014 \\
\hline $\mathrm{C}$ & NORIT A SUPRA, purchased & O: 17 & 952 \\
\hline
\end{tabular}

\section{Isotopic H/D scrambling}

H/D exchanged experiments were performed in a capillary reactor that was connected through a three-way valve to a quadrupolar mass spectrometer (MS) acting as detector. A diagram of the setup used is presented in the experimental section. Comparison of the H/D exchange activity of the samples was made based on sample weight (see Table 2), although it should be noted that the specific surface area varies depending on the material (see Table 1). Initially, the samples were pretreated at $200{ }^{\circ} \mathrm{C}$ under Ar flow for sufficiently long time until no signal is detected in MS, this lack of MS signal taken as indication that the surface of the material has been cleaned up. Then, each sample was submitted to a series of consecutive steps of which the initial ones were performed at $25{ }^{\circ} \mathrm{C}$ and the last ones at $200{ }^{\circ} \mathrm{C}$. The steps consist in exposing the clean sample to pulses of $\mathrm{D}_{2}$, then to $\mathrm{H}_{2}$ and finally Ar purging (Figure 1). Each step was prolonged for the required time to have a stationary response in MS for 5 min. The 
experimental section provides the detailed list of all the steps to which the samples were sequentially submitted.

MS not only allows continuous monitoring of $\mathrm{H}_{2}, \mathrm{HD}$ and $\mathrm{D}_{2}$, but also provides a quantitative value of the concentration of each molecular hydrogen isotopomer, being possible to calculate the amount adsorbed or desorbed in each step based on the integration of the signal corresponding to each isotopic hydrogen and the known gas flow. As an example Figure 1 shows the signals measured for $\mathrm{G}$ during the change from $\mathrm{D}_{2}$ adsorption to $\mathrm{H}_{2}$ adsorption showing the temporal evolution of $\mathrm{H}_{2}$, $\mathrm{HD}$ and $\mathrm{D}_{2}$. Figure 1 gives an indication of the signal to noise ratio and the accuracy of the measurements of the amounts of HD formed. A complete set of data of adsorption/desorption of $\mathrm{H}_{2}$ and $\mathrm{D}_{2}$ and the isotopic exchange level is summarized in Table 2 . Importantly, blank controls in the absence of catalyst show no $\mathrm{H} / \mathrm{D}$ exchange due to any possible activity of the reactor walls upon simultaneous admission of $\mathrm{H}_{2}$ and $\mathrm{D}_{2}$, this indicating that the signal at 3 amu corresponds really to HD formed by $\mathrm{H}-\mathrm{H}$ bond activation.

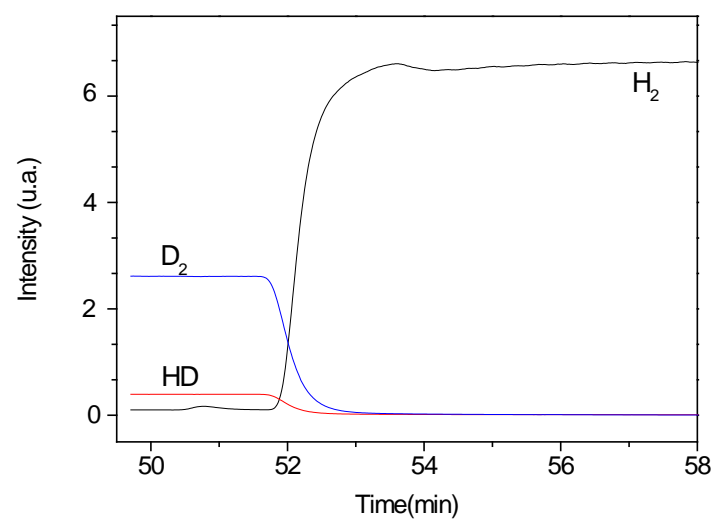

Figure 1. Temporal MS profiles of $\mathrm{H}_{2}, \mathrm{HD}$ and $\mathrm{D}_{2}$ monitored for $\mathrm{G}$ exposed at room temperature to a flow of $\mathrm{D}_{2}$ and, then, $\mathrm{H}_{2}$. 
Control measurements showed that the amount of $\mathrm{H}_{2}$ or $\mathrm{D}_{2}$ adsorbed on each sample at two temperatures is very similar, indicating that both isotopomers exhibit the same adsorption behavior. Importantly, as it can be seen in Table 2, the amount of $\mathrm{D}_{2}$ adsorbed on each sample after a pulse of the same amount of $\mathrm{D}_{2}$ is very different depending on the material. The amount $\mathrm{H}_{2} / \mathrm{D}_{2}$ adsorbed follows the order $\mathrm{G}>\mathrm{SWCNT}>\mathrm{GO}$,(N)G, C. G adsorbs about five-fold more than SWCNT and about ten-fold higher than the other samples. Importantly, H/D exchange was observed for all the samples based on the formation of HD, following the same relative reactivity order for H/D exchange as the one observed for adsorption, $\mathrm{G}$ forming HD amounts about five times higher than SWCNT and about ten times more active than GO, (N)G or C. This coincidence gives a hint suggesting that the adsorption sites are also responsible for activation of the $\mathrm{H}-\mathrm{H}$ bond. Quantification of the amount of $\mathrm{HD}$ formed at $25{ }^{\circ} \mathrm{C}$ in $\mathrm{G}$ was $0.1 \mathrm{ml} \times \mathrm{m}^{-2}$, while at $200{ }^{\circ} \mathrm{C}$ the amount of HD measured was $0.135 \mathrm{ml} \times \mathrm{m}^{-2}$.

Table 2. Data of H/D exchange activity for the different carbon materials under study.

\begin{tabular}{|c|c|c|c|c|c|c|c|c|c|c|c|}
\hline \multirow{2}{*}{\multicolumn{2}{|c|}{$\begin{array}{c}\text { Chemisorption } \\
\text { step }^{\mathrm{a}}\end{array}$}} & \multicolumn{10}{|c|}{ Sample } \\
\hline & & \multicolumn{2}{|c|}{$\mathrm{G}$} & \multicolumn{2}{|c|}{ SWCN } & \multicolumn{2}{|c|}{ GO } & \multicolumn{2}{|c|}{$(\mathrm{N}) \mathrm{G}$} & \multicolumn{2}{|c|}{$\mathrm{C}$} \\
\hline & & $\mathrm{mL} / \mathrm{m}^{2}$ & $\mathrm{~mL} / \mathrm{g}$ & ${ }_{2} \mathrm{~mL} / \mathrm{m}$ & $\mathrm{mL} / \mathrm{g}$ & $\mathrm{mL} / \mathrm{m}^{2}$ & $\mathrm{~mL} / \mathrm{g}$ & $\mathrm{mL} / \mathrm{m}^{2}$ & $\mathrm{~mL} / \mathrm{g}$ & $\mathrm{mL} / \mathrm{m}^{2}$ & $\mathrm{~mL} / \mathrm{g}$ \\
\hline \multirow[t]{3}{*}{$\mathrm{V}$} & $\mathrm{H}_{2}{ }^{\mathrm{b}}$ & 0.060 & 15.08 & 0.013 & 3.230 & 0.004 & 0.900 & 0.007 & 1.643 & 0.006 & 1.399 \\
\hline & $\mathrm{HD}^{\mathrm{C}}$ & 0.130 & 32.48 & 0.029 & 7.140 & 0.003 & 0.650 & 0.014 & 3.437 & 0.014 & 3.456 \\
\hline & $\mathrm{D}_{2}{ }^{\mathrm{d}}$ & 1.788 & 446.9 & 0.332 & 83.00 & 0.197 & 49.25 & 0.177 & 44.25 & 0.214 & 53.46 \\
\hline VI & $\mathrm{H}_{2}^{\mathrm{b}}$ & - & - & 0.013 & 3.180 & - & - & - & 1.640 & 0.005 & 1.326 \\
\hline
\end{tabular}




\begin{tabular}{cccccccccccc} 
& $\mathrm{HD}^{\mathrm{c}}$ & 0.100 & 25.06 & 0.021 & 5.360 & 0.013 & 3.200 & 0.007 & 2.642 & 0.013 & 3.167 \\
& $\mathrm{D}_{2}{ }^{\mathrm{d}}$ & 1.610 & 402.6 & 0.338 & 84.44 & 0.198 & 49.56 & 0.011 & 42.11 & 0.170 & 42.46 \\
\hline VIII & $\mathrm{H}_{2}{ }^{\mathrm{b}}$ & 1.975 & 493.7 & 0.376 & 94.06 & 0.206 & 51.60 & 0.182 & 45.40 & 0.172 & 42.88 \\
& $\mathrm{HD}^{\mathrm{c}}$ & 0.135 & 33.84 & 0.030 & 7.390 & 0.008 & 2.040 & 0.014 & 3.535 & 0.015 & 3.780 \\
& $\mathrm{D}_{2}{ }^{\mathrm{d}}$ & 1.843 & 460.8 & 0.358 & 89.58 & 0.207 & 51.83 & 0.189 & 47.35 & 0.253 & 63.26 \\
\hline $\mathrm{IX}$ & $\mathrm{H}_{2}{ }^{\mathrm{b}}$ & - & - & 0.012 & 2.960 & - & - & 0.006 & 1.486 & 0.005 & 1.234 \\
& $\mathrm{HD}^{\mathrm{b}}$ & 0.115 & 28.65 & 0.022 & 5.490 & 0.012 & 3.030 & 0.011 & 2.737 & 0.013 & 3.166 \\
& $\mathrm{D}_{2}{ }^{\mathrm{c}}$ & 1.832 & 457.9 & 0.342 & 85.44 & 0.180 & 45.12 & 0.171 & 42.78 & 0.155 & 38.74 \\
\hline
\end{tabular}

${ }^{\text {a }}$ The complete sequence of steps (desorption, adsorption, etc.) to which the samples were submitted is indicated in the experimental section: Step V) Injection of $\mathrm{D}_{2}$ in $\mathrm{Ar}$ at $25{ }^{\circ} \mathrm{C}$; $\underline{\text { Step }}$ VI) The flow of $\mathrm{D}_{2}$ is stopped and a stream of Ar is flushed at $25^{\circ} \mathrm{C}$; Step VIII) Injection of $\mathrm{D}_{2}$

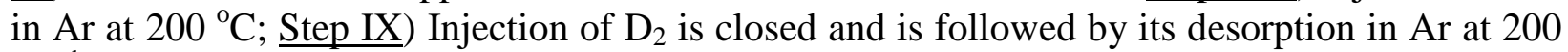
${ }^{\circ} \mathrm{C}$; ${ }^{\mathrm{b}}$ amount formed during the whole step quantified by MS; ${ }^{\mathrm{c}}$ Amount adsorbed in the material during the whole step quantified by MS.

Theoretical calculations.

The experiments probing the activity of $G$ to promote H/D exchange were complemented with DFT calculations determining a possible mechanism for $\mathrm{H}_{2}$ activation, the corresponding transition states and the structure of chemisorbed $\mathrm{H}_{2}$ on a $\mathrm{G}$ model having a $\mathrm{C}$ atom vacancy. Carbon vacancies have been widely deemed as catalytic sites due to the existence of dangling bonds. ${ }^{3}$

The first reaction pathway explored corresponds to the chemisorption of molecular hydrogen on a carbon atom vacancy graphene model where $\mathrm{H}_{2}$ approaches the site perpendicular to the graphene surface. In this pathway only one $\mathrm{H}$ atom of $\mathrm{H}_{2}$ attacks a carbon atom peripheral to the vacancy (Figure 2, top), minimizing the unfavourable interaction of two $\mathrm{H}$ atoms approaching 
the $\mathrm{G}$ surface at the defect site. The results for the $\mathrm{H}_{2}$ dissociation on the graphene model calculated with the functional PBE1PBE and the basis set $6-311+G(d, p)$ are shown in Table 3 and Figure 2.

Table 3. Calculated (PBE1PBE/6-311+G(d,p)) relative energies $(\mathrm{kJ} / \mathrm{mol})$ and geometry $(\AA)$ of the reactants, products, and transition state of the $\mathrm{H}_{2}$ dissociation on a vacancy defect of a cluster of graphene as indicated in Figure 2.

\begin{tabular}{|c|c|c|c|}
\hline & eactants & Transition State & Products \\
\hline C-H & 3.07 & $1.46,1.61$ & $1.11,1.11$ \\
\hline C-C & 1.92 & 1.89 & 1.87 \\
\hline $\mathrm{H}-\mathrm{H}$ & 0.76 & 0.96 & 1.92 \\
\hline Energy & 0.0 & 124.1 & -67.7 \\
\hline
\end{tabular}

A high activation energy of $124.1 \mathrm{~kJ} / \mathrm{mol}$ was estimated. The adsorption of $\mathrm{H}_{2}$ in the graphene surface is very weak, as shown by the large $\mathrm{H}_{2}$-graphene distance of $3.07 \AA$ (Table 3), which means that $\mathrm{H}_{2}$ is weakly activated, and hence the large uphill energy until the transition state is reached. 

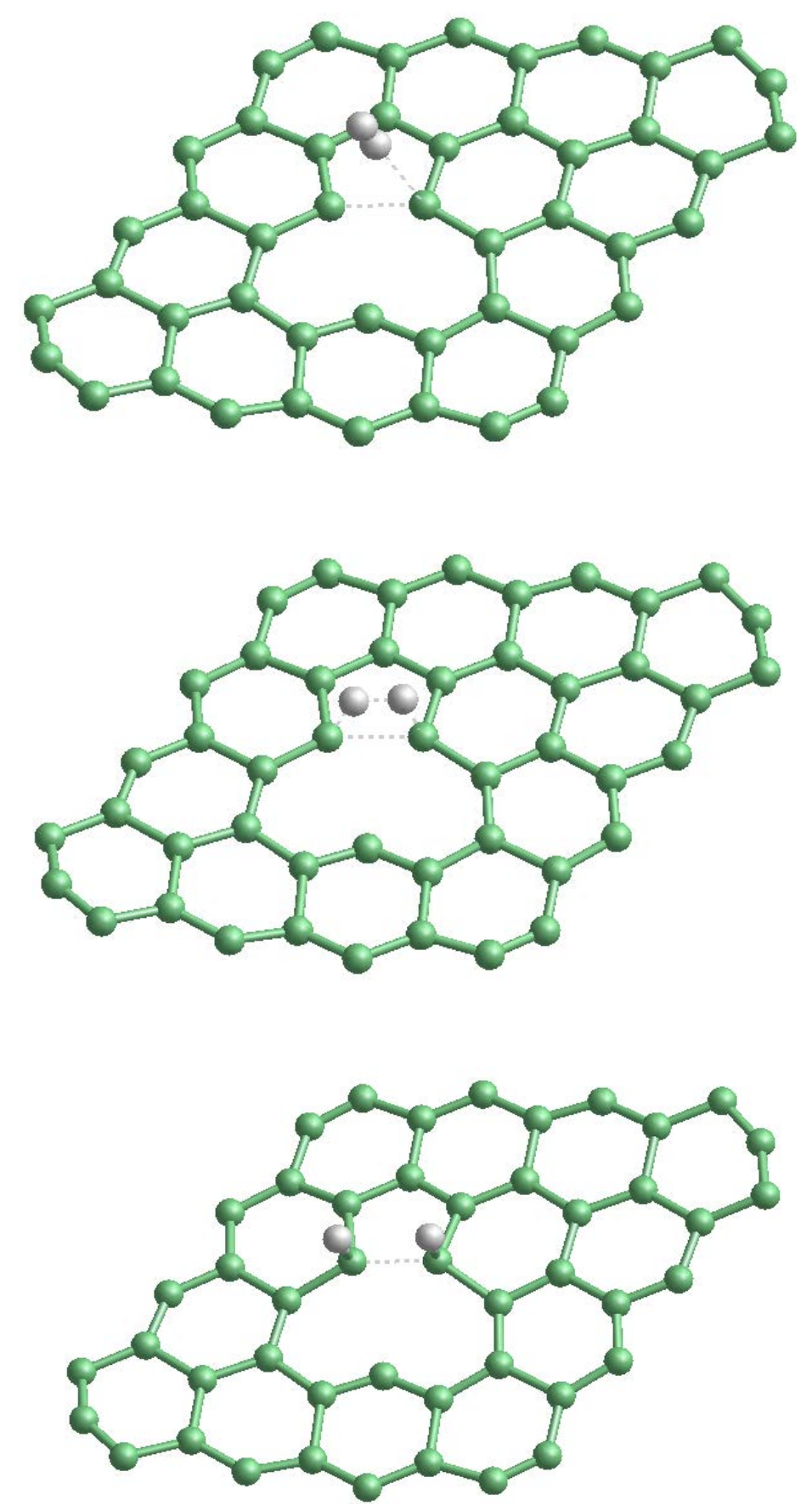

Figure 2. Calculated (PBE1PBE/6-311+G(d,p) geometries of the: reactants (top); transition state (middle); and products (bottom), corresponding to the reaction of dissociation of $\mathrm{H}_{2}$ on a defective graphene surface. The highlighted (dashed line) relevant distances are: $d(C-C)=1.92$ 
$\AA, \mathrm{d}(\mathrm{C}-\mathrm{H})=3.07 \AA, \mathrm{d}(\mathrm{H}-\mathrm{H})=0.76 \AA$ (top); $\mathrm{d}(\mathrm{C}-\mathrm{C})=1.89 \AA, \mathrm{d}(\mathrm{C}-\mathrm{H})=1.46,1.61 \AA, \mathrm{d}(\mathrm{H}-\mathrm{H})=$ $0.96 \AA$ (middle); $\mathrm{d}(\mathrm{C}-\mathrm{C})=1.87 \AA, \mathrm{d}(\mathrm{C}-\mathrm{H})=1.11 \AA, \mathrm{d}(\mathrm{H}-\mathrm{H})=1.92 \AA$ (bottom).

The influence of the basis set was investigated by making new calculations using the less sophisticated 6-31G(d,p), without diffuse functions, obtaining an activation energy of 157.8 $\mathrm{kJ} / \mathrm{mol}$. This higher activation energy is an expected result since the inclusion of diffuse functions gives more capability to the carbon atoms to form certain bonding with the incoming $\mathrm{H}_{2}$ through the unoccupied orbitals that are better modelled when including diffuse functions.

The reaction products (Figure 2, bottom), show a C-H bond which can be easily activated for further reaction due to two main reasons. One of them is that the $\mathrm{C}-\mathrm{H}$ bond is perpendicular to the graphene plane, far from the equilibrium geometry where a hybridisation for the corresponding carbon in between $\mathrm{sp}^{2}$ and $\mathrm{sp}^{3}$ can be expected. The second reason is that, in these formed C-H bonds, the two hydrogen atoms are at a distance of $1.92 \AA$, this implying a certain $\mathrm{H}-\mathrm{H}$ bonding, weakening the C-H bonds. Accordingly, the newly formed C- $\mathrm{H}$ bonds after $\mathrm{H}_{2}$ dissociation should exhibit an enhanced reactivity that will facilitate hydrogenation of upcoming reactants.

Notably, when the same calculations are repeated allowing the graphene model to curve, it was found that the transition state becomes relaxed by resembling the convex surface of a SWCNT and not longer a flat graphene surface (Figure 3). The convex curvature is responsible for a

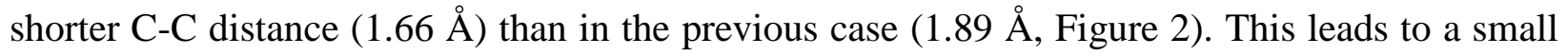
elongation of the $\mathrm{H}-\mathrm{H}$ bond of the hydrogen molecule in the transition state (Figure 3), making less favorable the interaction with both $\mathrm{C}$ atoms to begin the formation of the $\mathrm{C}-\mathrm{H}$ bonds, all of 
this resulting in an earlier transition state, giving a lower activation barrier of $102.3 \mathrm{~kJ} / \mathrm{mol}$. This result, obtained with the less accurate basis set, 6-31G(d,p), should be compared with the activation barrier value of $157.8 \mathrm{~kJ} / \mathrm{mol}$ obtained for the same basis set in the flat surface. This comparison indicates a clear reduction of the activation barrier due to the curvature of the surface. While this curvature is unrealistic for graphene sheets because it would require a considerable distortion, calculations with this model indicate that H/D exchange should be faster for carbon nanotubes, thus, contributing to explain the higher reactivity of SWCNT in this reaction compared to GO, $(\mathrm{N}) \mathrm{G}$ and $\mathrm{C}$ as shown in Table 2 compiling the experimental values for $\mathrm{H} / \mathrm{D}$ exchange.

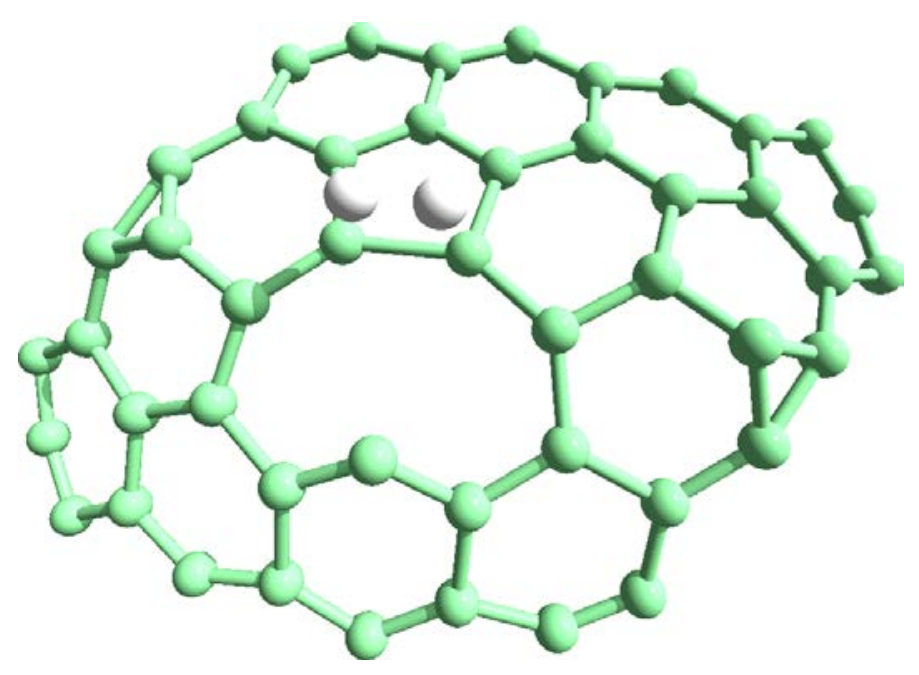

Figure 3. Calculated (PBE1PBE/6-31G(d,p) geometry of the transition state of the $\mathrm{H}_{2}$ dissociation reaction on a defective graphene surface. Unlike Figure 2, in this reaction path the borders of the graphene model were allowed to curve. Relevant distances: $d(C-C)=1.66 \AA, d(C-$ $\mathrm{H})=1.47,1.48 \AA, \mathrm{d}(\mathrm{H}-\mathrm{H})=0.99 \AA$. 
A second reaction path has been explored in which the $\mathrm{H}_{2}$ molecule approaches two different carbon atoms in the same vacancy, this resulting in a different C-C distance (Table 4). Figure 4 presents the geometries of the transition state and products. The transition state obtained (Figure 4, top) indicates an earlier transition state than in the case of Figures 2 and 3, as demonstrated by the smaller elongation of the $\mathrm{H}-\mathrm{H}$ bond, $0.88 \AA$ in this case, compared to 0.96 or $0.99 \AA$ in the previous cases for flat or curved surfaces. This requirement of smaller $\mathrm{H}-\mathrm{H}$ elongation is a consequence of the larger distance between the two relevant $\mathrm{C}$ atoms involved that are further apart to each other (2.69 $\AA$ in this case, against $1.89 \AA$ in the previous mechanism), increasing their affinity to create $\mathrm{C}-\mathrm{H}$ bonds due to the lower coordination of the two active $\mathrm{C}$ atoms. For this second pathway the activation barrier is $83.9 \mathrm{~kJ} / \mathrm{mol}$ (Table 4). However, on the other side, the $\mathrm{C}-\mathrm{H}$ products seem more stable than in the previous path, this making less favourable the upcoming isotopic H-D exchange. This second pathway appears as more reasonable considering its lower activation energy, which suits better with the occurrence of room temperature H/D isotope exchange observed experimentally.

Table 4. Calculated (PBE1PBE/6-311+G(d,p)) relative energies $(\mathrm{kJ} / \mathrm{mol})$ and geometry $(\AA)$ of the reactants, products, and transition state of the $\mathrm{H}_{2}$ dissociation on a vacancy defect of a cluster of graphene as indicated in Figure 4.

\begin{tabular}{|c|c|c|}
\hline Reactants & Transition State & Products \\
\hline 3.07 & $1.51,1.76$ & $1.11,1.12$ \\
\hline 2.72 & 2.69 & 2.69 \\
\hline
\end{tabular}


$\begin{array}{llll}\mathrm{H}-\mathrm{H} & 0.76 & 0.88 & 1.48\end{array}$

$\begin{array}{llll}\text { Energy } & 0.0 & 83.9 & -249.7\end{array}$
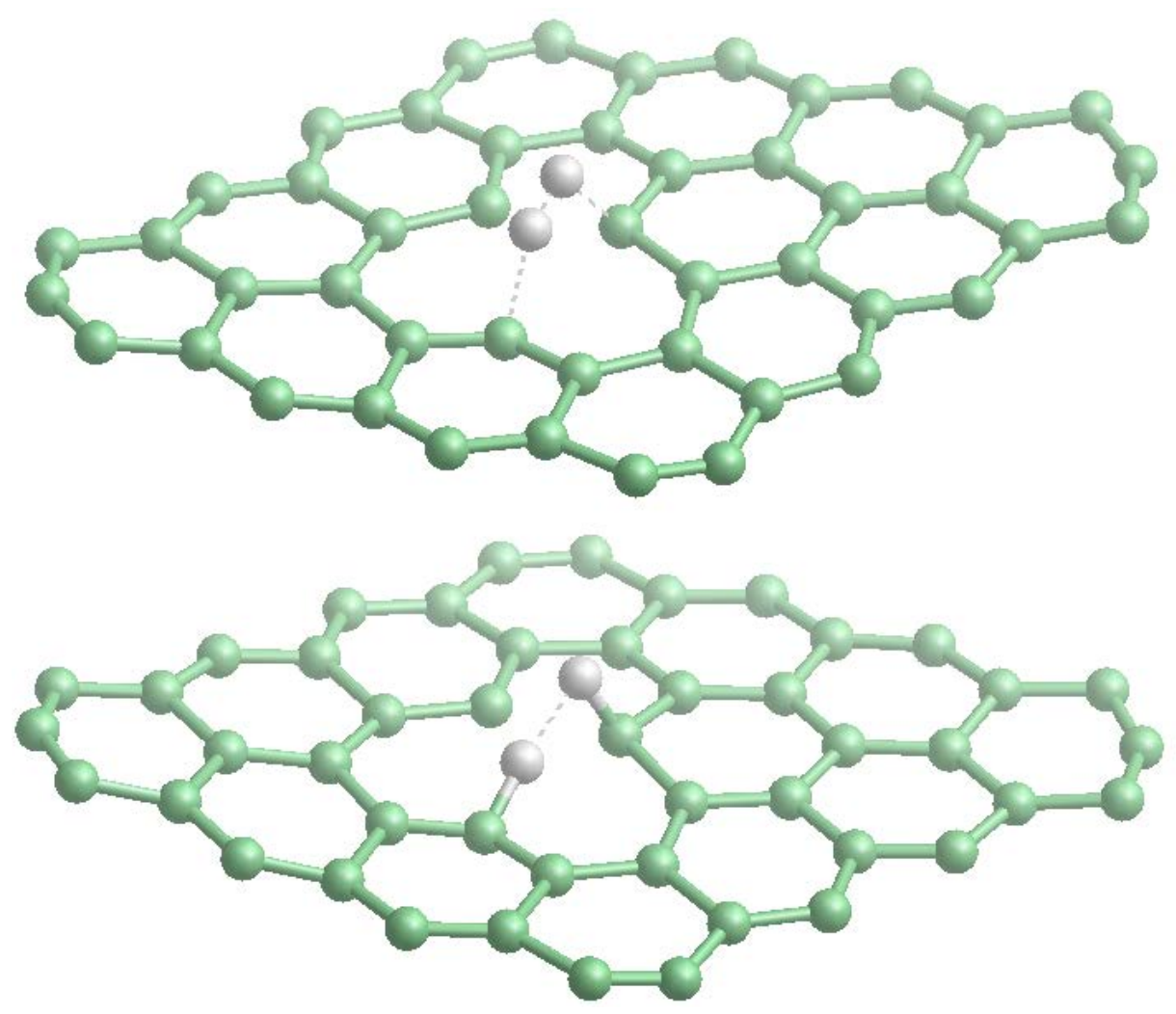

Figure 4. Calculated (PBE1PBE/6-311+G(d,p) geometries of the transition state (top); and products (bottom), corresponding to the reaction of dissociation of $\mathrm{H}_{2}$ on a defective graphene surface. The highlighted (dashed line) relevant distances are: $d(C-C)=2.69 \AA, d(C-H)=1.51$, $1.76 \AA, \mathrm{d}(\mathrm{H}-\mathrm{H})=0.88 \AA$ (top); $\mathrm{d}(\mathrm{C}-\mathrm{C})=2.69 \AA, \mathrm{d}(\mathrm{C}-\mathrm{H})=1.11,1,12 \AA, \mathrm{d}(\mathrm{H}-\mathrm{H})=1.48 \AA$ (bottom). 
In summary, experimental evidence of the room temperature $\mathrm{H}-\mathrm{H}$ bond dissociation on defective graphene has been provided by H/D isotopic exchange. It has been shown that $\mathrm{H}_{2}$ activation depends on the nature of the graphene, the most active sample of the series being a defective graphene. DFT calculations suggest that $\mathrm{H}_{2}$ activation can take place at carbon atom vacancies, the activation energy depending on the way in which $\mathrm{H}_{2}$ approaches the site and the steric encumbrance for the allocation of $\mathrm{C}-\mathrm{H}$ bonds. A short nonbonding $\mathrm{C}-\mathrm{C}$ distance in the defect results in a high barrier and activated products, while a short C-C distance results in a low barrier and less reactive products.

\section{EXPERIMENTAL SECTION.}

\section{Materials}

GO was obtained from commercial graphite by Hummers-Offeman oxidation with permangate, followed by exfoliation by sonication as reported. ${ }^{21} \mathrm{G}$ and $(\mathrm{N}) \mathrm{G}$ samples were obtained by pyrolysis at $1000{ }^{\circ} \mathrm{C}$ in an electrical horizontal furnace powders of commercial alginic acid and chitosan, followed by exfoliation by sonication of the resulting graphitic carbonaceous residues. ${ }^{19}$ SWCN and AC were commercial samples.

\section{Isotopic $\mathrm{H} / \mathrm{D}$ exchange}

Isotopic $\mathrm{H}$-D exchange measurements were carried out in a home-made isotopic hydrogen-deuterium (H/D) exchange setup whose diagram is shown in Figure 5. 


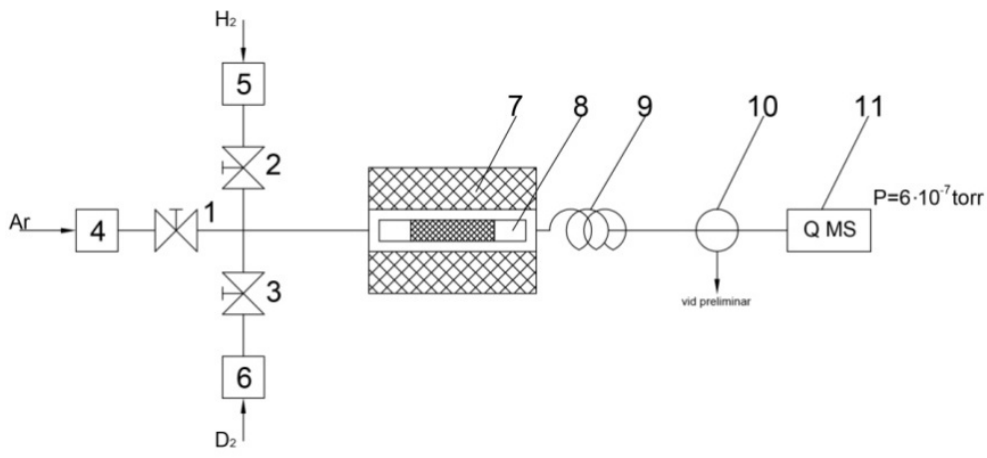

Figure 5. Schematics of the home-made set up for isotopic H/D exchange setup used in the present study: 1,2,3, - electromagnetic taps, 4,5,6,- flow controllers,7- electric oven, 8-reactor, 9 -capillary, 10- three way tap, 11- Q MS mass quadrupolar spectrometer (Pfeiffer Vacuum).

The samples were introduced in a chromatography-like column reactor and pre-treated under a $50 \mathrm{~cm}^{3} / \mathrm{min}$ argon (99.999\% purity) flow at $300{ }^{\circ} \mathrm{C}$ till MS shows that the sample does not desorb any impurity. Then the reactor was cooled at the measurement temperature and pulses of $2 \mathrm{~cm}^{3} / \mathrm{min}$ of hydrogen (99.9998\% purity) or deuterium (isotopic purity 96 at.\% of D) were injected in the argon flow. The process was monitored following the evolution of the 2( $\left.\mathrm{H}_{2}\right)$, 3(HD) si $4\left(\mathrm{D}_{2}\right)$ mass peaks. A full experiment consisted in a series of consecutive steps numbered from I to XI. The steps were the following: I - Degassing the samples under the argon flow (where mainly the desorption of the physisorbed water is monitored); II - $\mathrm{D}_{2}$ is injected in the Ar flow taking place the chemisorption of this isotope; III - Injection of $\mathrm{D}_{2}$ is stopped concomitantly with the admission of $\mathrm{H}_{2}$ in $\mathrm{Ar}$ (where a simultaneous desorption of $\mathrm{D}_{2}$ and chemisorption of $\mathrm{H}_{2}$ takes place); IV - Injection of $\mathrm{H}_{2}$ is closed and continues the desorption of physisorbed $\mathrm{H}_{2} ; \mathrm{V}$ - Injection of $\mathrm{D}_{2}$ in Ar with the aim to control the amount of $\mathrm{H}_{2}$ that is chemisorbed on the surface and of the $\mathrm{H}_{2}$ substituted by $\mathrm{D}_{2}$; VI -Injection of $\mathrm{D}_{2}$ is closed and is followed by its desorption in Ar; Experiments VII - X were identical with experiments III-VI 
except that the reactor temperature was $200^{\circ} \mathrm{C}$; $\mathrm{XI}$ - Admission of $\mathrm{H}_{2}$ was stopped and the reactor cool down at $25^{\circ} \mathrm{C}$ flow of Ar. Every step was considered ended when after at least 5 min the MS intensity of the lines assigned to the three components remained unchanged.

Quantification of the hydrogen isotopic compounds $\left(\mathrm{H}_{2}, \mathrm{HD}, \mathrm{D}_{2}\right)$ was made by integration of the curves collected from the MS analyses vs. time, which multiplied by the flow of hydrogen (or deuterium) entered in the reactor provides the volume adsorbed ( $\left.V_{a d s}\right)$ or desorbed $\left(V_{\text {des }}\right)$ for each isotopomer on/from the investigated samples (Eqs.1-2).

$$
\begin{aligned}
& \mathrm{V}_{\mathrm{ads}}=Q_{H_{2}\left(D_{2}\right)} \int_{0}^{t_{\text {max }}}\left(1-\frac{I(t)}{I_{\max }}\right) d t \\
& \mathrm{~V}_{\mathrm{des}}=Q_{H_{2}\left(D_{2}\right)} \int_{0}^{t_{\text {max }}} \frac{I(t)}{I_{\max }} d t
\end{aligned}
$$

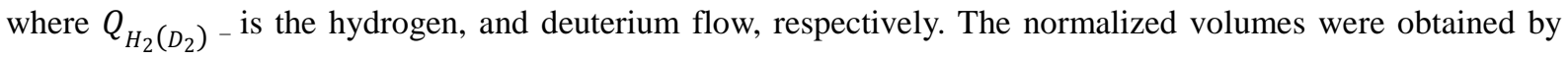
dividing the calculated $\mathrm{V}_{\mathrm{ads}}$ and $\mathrm{V}_{\mathrm{des}}$ values to the mass of the samples and surface areas.

Computational methods.

Long-range interactions, such as those involved in physisorption, are poorly described in most of the presently available exchange-correlation functionals within Density Functional Theory (DFT). It is known, however, that no DFT functional accurately describes all the characteristics of molecular interactions, in particular van der Waals (London dispersion) interactions, which are, in part, due to electronic correlation.

New DFT functionals where an improved description of the long range dispersion interactions is included $^{22}$ have been employed in this study. Current GGA (generalized gradient approximation) functionals, that take into account the gradient of the electron density at the point of evaluation, such as PW91 or PBE, seem to perform reasonably well, while LDA functionals 
seem not appropriate for the treatment of systems dominated by London dispersion forces. PW91 and PBE are two of the GGA type functionals which give better results for weakly bound systems because they are free from some of the repulsive contributions (both functionals satisfy the Lieb-Oxford bound) that make other GGA functionals unable to capture weak interactions. ${ }^{23}$ In this case, PBE0 has been used, ${ }^{24}$ together with the $6-311+G(d, p)^{25,} 26$ basis set, within the Gaussian $09^{27}$ software package.

\section{ACKNOWLEDGMENTS}

Financial support by the Spanish Ministry of Economy and Competitiveness (Severo Ochoa SEV-2012-0267 and CTQ2015-69153-C2-R1) and Generalitat Valenciana (Prometeo 2013/014) is gratefully acknowledged. G. S. thanks the Scientific Division of SGAI CSIC for computing facilities.

\section{REFERENCES}

1. Dreyer, D. R.; Bielawski, C. W., Carbocatalysis: Heterogeneous carbons finding utility in synthetic chemistry. Chemical Science 2011, 2 (7), 1233-1240.

2. $\quad$ Dreyer, D. R.; Jia, H.-P.; Bielawski, C. W., Graphene Oxide: A Convenient Carbocatalyst for Facilitating Oxidation and Hydration Reactions. Angewandte Chemie-International Edition 2010, 49 (38), 6813-6816.

3. Navalon, S.; Dhakshinamoorthy, A.; Alvaro, M.; Garcia, H., Carbocatalysis by Graphene-Based Materials. Chemical Reviews 2014, 114 (12), 6179-6212.

4. Su, D. S.; Perathoner, S.; Centi, G., Nanocarbons for the Development of Advanced Catalysts. Chemical Reviews 2013, 113 (8), 5782-5816.

5. Geier, S. J.; Stephan, D. W., Lutidine/B(C6F5)(3): At the Boundary of Classical and Frustrated Lewis Pair Reactivity. Journal of the American Chemical Society 2009, 131 (10), 3476-+.

6. Stephan, D. W., Frustrated Lewis pairs: a new strategy to small molecule activation and hydrogenation catalysis. Dalton Transactions 2009, (17), 3129-3136.

7. Stephan, D. W.; Erker, G., Frustrated Lewis Pairs: Metal-free Hydrogen Activation and More. Angewandte Chemie-International Edition 2010, 49 (1), 46-76. 
8. $\quad$ Blaser, H. U.; Malan, C.; Pugin, B.; Spindler, F.; Steiner, H.; Studer, M., Selective hydrogenation for fine chemicals: Recent trends and new developments. Advanced Synthesis \& Catalysis 2003, 345 (1-2), 103-151.

9. Auer, E.; Freund, A.; Pietsch, J.; Tacke, T., Carbons as supports for industrial precious metal catalysts. Applied Catalysis a-General 1998, 173 (2), 259-271.

10. Primo, A.; Neatu, F.; Florea, M.; Parvulescu, V.; Garcia, H., Graphenes in the absence of metals as carbocatalysts for selective acetylene hydrogenation and alkene hydrogenation. Nature Communications 2014, 5.

11. Schniepp, H. C.; Li, J.-L.; McAllister, M. J.; Sai, H.; Herrera-Alonso, M.; Adamson, D. H.; Prud'homme, R. K.; Car, R.; Saville, D. A.; Aksay, I. A., Functionalized Single Graphene Sheets Derived from Splitting Graphite Oxide. The Journal of Physical Chemistry B 2006, 110 (17), 8535-8539.

12. Srinivas, G.; Zhu, Y.; Piner, R.; Skipper, N.; Ellerby, M.; Ruoff, R., Synthesis of graphene-like nanosheets and their hydrogen adsorption capacity. Carbon 2010, 48 (3), 630-635.

13. Durgun, E.; Ciraci, S.; Yildirim, T., Functionalization of carbon-based nanostructures with light transition-metal atoms for hydrogen storage. Physical Review B 2008, 77 (8).

14. Ghosh, A.; Subrahmanyam, K. S.; Krishna, K. S.; Datta, S.; Govindaraj, A.; Pati, S. K.; Rao, C. N. R., Uptake of H-2 and CO2 by graphene. Journal of Physical Chemistry C 2008, 112 (40), 15704-15707.

15. Raidongia, K.; Nag, A.; Hembram, K. P. S. S.; Waghmare, U. V.; Datta, R.; Rao, C. N. R., BCN: A Graphene Analogue with Remarkable Adsorptive Properties. Chemistry-a European Journal 2010, 16 (1), 149-157.

16. Elias, D. C.; Nair, R. R.; Mohiuddin, T. M. G.; Morozov, S. V.; Blake, P.; Halsall, M. P.; Ferrari, A. C.; Boukhvalov, D. W.; Katsnelson, M. I.; Geim, A. K.; Novoselov, K. S., Control of Graphene's Properties by Reversible Hydrogenation: Evidence for Graphane. Science 2009, 323 (5914), 610-613.

17. Sofo, J. O.; Chaudhari, A. S.; Barber, G. D., Graphane: A two-dimensional hydrocarbon. Physical Review B 2007, 75 (15).

18. Primo, A.; Atienzar, P.; Sanchez, E.; Maria Delgado, J.; Garcia, H., From biomass wastes to large-area, high-quality, N-doped graphene: catalyst-free carbonization of chitosan coatings on arbitrary substrates. Chemical Communications 2012, 48 (74), 9254-9256.

19. Primo, A.; Sanchez, E.; Delgado, J. M.; Garcia, H., High-yield production of N-doped graphitic platelets by aqueous exfoliation of pyrolyzed chitosan. Carbon 2014, 68, 777-783.

20. Park, S.; Ruoff, R. S., Chemical methods for the production of graphenes. Nature Nanotechnology 2009, 4 (4), 217-224.

21. Stankovich, S.; Dikin, D. A.; Piner, R. D.; Kohlhaas, K. A.; Kleinhammes, A.; Jia, Y.; Wu, Y.; Nguyen, S. T.; Ruoff, R. S., Synthesis of graphene-based nanosheets via chemical reduction of exfoliated graphite oxide. Carbon 2007, 45 (7), 1558-1565.

22. Grimme, S., Accurate description of van der Waals complexes by density functional theory including empirical corrections. Journal of Computational Chemistry 2004, 25 (12), 1463-1473.

23. Negri, F.; Saendig, N., Tuning the physisorption of molecular hydrogen: binding to aromatic, hetero-aromatic and metal-organic framework materials. Theoretical Chemistry Accounts 2007, 118 (1), 149-163.

24. Adamo, C.; Barone, V., Toward reliable density functional methods without adjustable parameters: the PBE0 model. J. Chem. Phys. 1999, 110, 6158-6169. 
25. Clark, T.; Chandrasekhar; R., S. P. v., J. Comp. Chem. 1983, 4, 294.

26. Krishnan, R.; Binkley, J. S.; Seeger, R.; Pople, J. A., J. Chem. Phys. J. Chem. Phys. 1980, 72, 650.

27. 